\title{
Otocephaly: Agnathia-Microstomia-Synotia Syndrome
}

\author{
Tanya Kitova ${ }^{1}$, Borislav D Kitov ${ }^{2}$
}

\begin{abstract}
The aim of the study is to present otocephaly, which is a rare congenital lethal malformation. Until this moment, only a little bit more than 100 cases worldwide were reported, and only 22 cases of prediagnosed otocephaly.

Background: Otocephaly or agnathia-microstomia-synotia syndrome (SAMS) is characterized by agenesis of mandible (agnathia), disposition or fusion of the auricle (synotia), microstomia, and complete or partial lack of language (aglossia), which often ends up lethal.

Case description: A $499.7 \mathrm{~g}$ male fetus was obtained after a therapeutic abortion during the 23rd gestational week at the Center for Maternity and Neonatology, Embryo-fetopathology Clinic, Tunis, Tunisia. The mother is an 18-year-old with close relative marriage with first-degree incest, primigravida. Examination of the fetus revealed microcephaly with craniosynostosis, hypertelorism, closed eyelid exophthalmos, one nostril, point microstomia, mandibular agenesis, bilateral, and auditory cysts of neck. The ears are located at the level of the neck. A study of the brain and the base of the skull revealed holoprosencephaly and sphenoid bone agenesis. There are no internal organ abnormalities.

Conclusion: In cases where, at the end of the second trimester of pregnancy, polyhydramnios is detected, inability to visualize the mandible, and malposition of ears, otocephaly should be suspected. In these cases, the decision to interrupt pregnancy should be taken by a multidisciplinary team, after an magnetic resonance imaging, which is much better in visualizing location of the ears and other facial malformations and the presence of other associated anomalies.

Clinical significance: Otocephaly (SAMS) is usually incompatible with life, which is why it is important to perform prenatal diagnosis in order to make prognosis for pregnancy.

Keywords: Agnathia, Congenital malformation, Otocephaly, Prenatal ultrasound.

International Journal of Infertility and Fetal Medicine (2021): 10.5005/jp-journals-10016-1195
\end{abstract}

\section{BACKGROUND}

Otocephaly or agnathia-microstomia-synotia syndrome (SAMS) is a rare congenital malformation characterized by agenesis of mandible (agnathia), disposition or fusion of the auricle (synotia), microstomia, and complete or partial lack of language (aglossia), which often ends up lethal, due to respiratory problems. ${ }^{1}$ Syndrome is the most severe form of anomalies of the former pharyngeal arches as a result of the cessation of its development and the failure of the comb cells to migrate into the first pharyngeal pouch. ${ }^{2}$ The anomaly is due to gene or chromosomal de novo mutation, which appears after exposure to teratogenic or chemical agents. ${ }^{3}$

\section{Case Description}

This applies to the male fetus with weight of $499.7 \mathrm{~g}$, delivered after therapeutic abortion during 23rd gestational week at the Center of Maternity and Neonatology, Embryo-fetopathology Clinic, city of Tunis, Tunisia. The fetus is a primipara of 18 -year-old woman, whose husband is a first-degree relative, having no family history of congenital malformations, no evidence of teratogenic medication, recent infections, diabetes mellitus, or hypertension. Prenatal sonographic examination, which was performed by the end of the second trimester, showed pronounced malformative syndrome, which is why medical abortion was performed in the 23rd gw without performing karyotyping. Parameters of studied fetus (VT $=32 \mathrm{~cm}, \mathrm{VC}=20.5 \mathrm{~cm}, \mathrm{PC}=17 \mathrm{~cm}, p=4.4 \mathrm{~cm}$ ) correspond to the development over 23-24 GS (Fig. 1).

Fetal examination revealed microcephaly with lack of anterior and posterior fontanelles, hypertelorism, exophthalmos with closed eyelids, single nostril, point microstomia, mandibular agenesis, and neck deformity. The ears are located at the level of the neck, being
${ }^{1}$ Department of Anatomy, Histology and Embryology, Medical University of Plovdiv, Plovdiv, Bulgaria

${ }^{2}$ Department of Neurosurgery, Medical University of Plovdiv, Plovdiv, Bulgaria

Corresponding Author: Tanya Kitova, Department of Anatomy, Histology and Embryology, Medical University of Plovdiv, Plovdiv, Bulgaria, e-mail: tanyakitova@yahoo.com

How to cite this article: Kitova T, Kitov BD. Otocephaly: AgnathiaMicrostomia-Synotia Syndrome. Int J Infertil Fetal Med 2021;12(2): 40-43.

Source of support: Nil

Conflict of interest: None

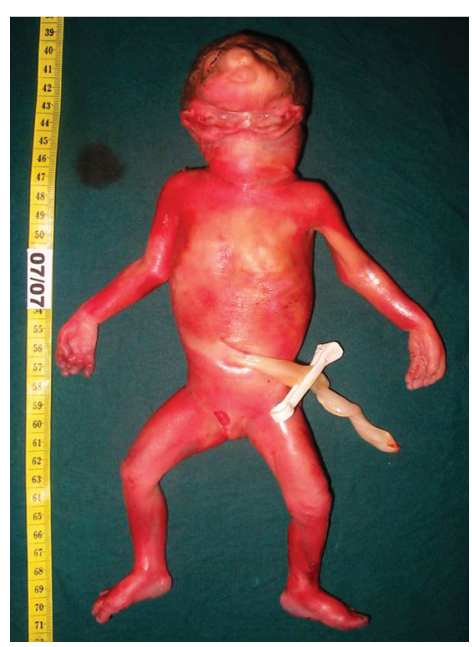

Fig. 1: Appearance of the studied fetus

(0) Jaypee Brothers Medical Publishers. 2021 Open Access This article is distributed under the terms of the Creative Commons Attribution 4.0 International License (https://creativecommons.org/licenses/by-nc/4.0/), which permits unrestricted use, distribution, and non-commercial reproduction in any medium, provided you give appropriate credit to the original author(s) and the source, provide a link to the Creative Commons license, and indicate if changes were made. The Creative Commons Public Domain Dedication waiver (http://creativecommons.org/publicdomain/zero/1.0/) applies to the data made available in this article, unless otherwise stated. 

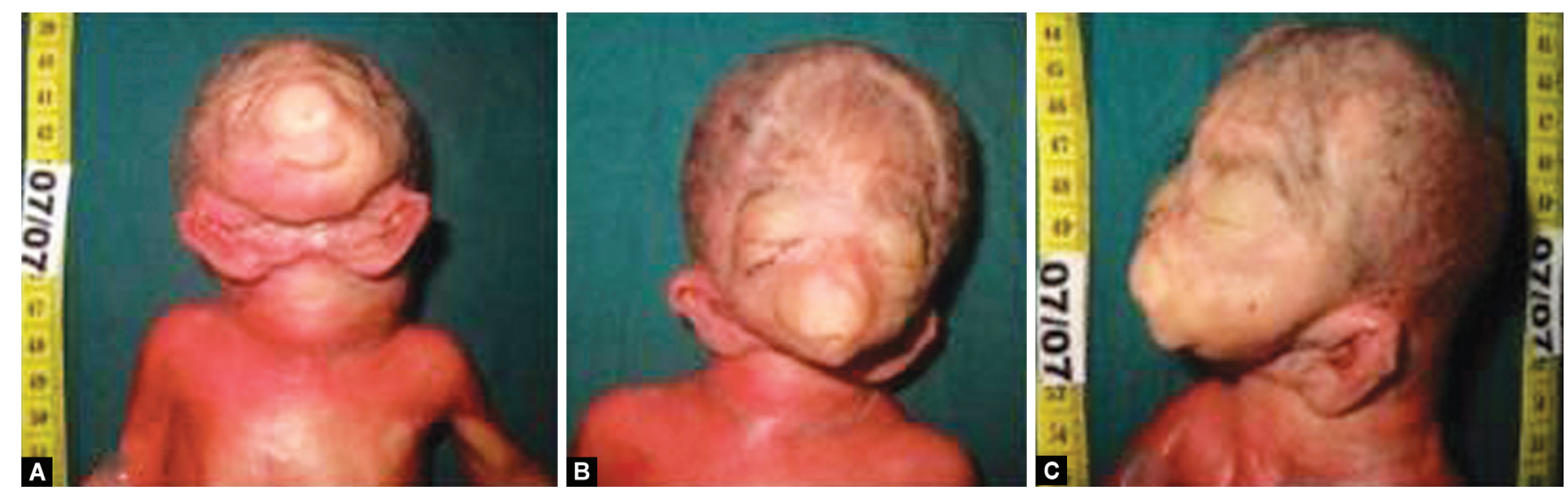

Figs 2A to C: Anterior view: (A) The ears at the level of the neck, captured by an interauricular bridge; (B) Microcephaly, hypertelorism, exophthalmos with closed eyelids, single nostril, point microstomia, mandibular agenesis, neck deformity; (C) External auditory canals located submandibular
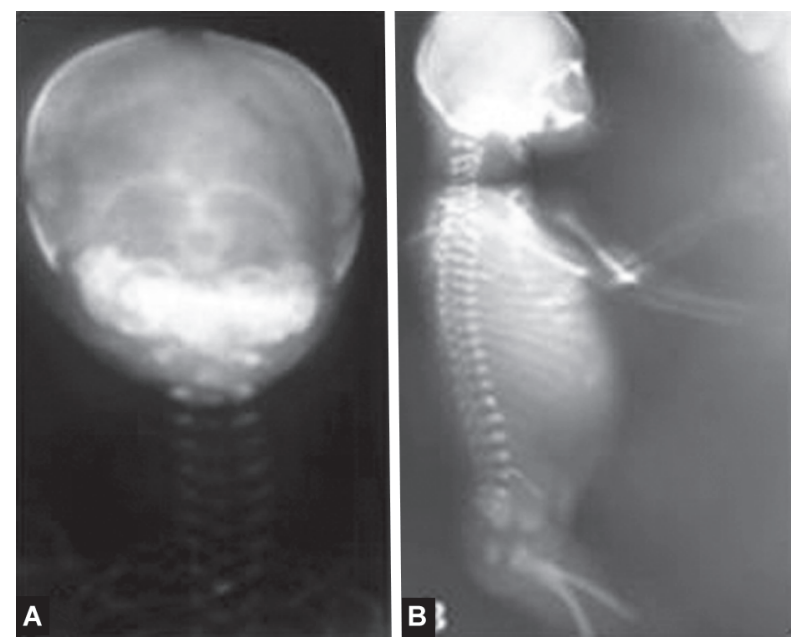

Figs $3 \mathrm{~A}$ and $\mathrm{B}$ : Radiography (face and profile)-agenesis of the mandible, the bones of the nasal cavity, sphenoid bone

captured by an interauricular bridge. External auditory canals are located submandibular (Fig. 2).

$\mathrm{X}$-ray revealed mandibular agenesis, sphenoid bone agenesis, and bones of the nasal cavity agenesis (Fig. 3). Fetal autopsy showed bilateral, auditory cysts of neck located medially and forward of the ear lobe, which are abnormal derivatives of the first pharyngeal cleft (Fig. 4). Examination of the internal organs did not establish the presence of anomalies. A study of the brain and cranial base revealed holoprosencephaly and agenesis of sphenoid bone (Fig. 5).

\section{Discussion}

SAMS is a rare malformative complex of the first pharyngeal arch, occurring during the development of the person between the fourth and eighth gestational week, with a frequency of 1 in 70,000 births. ${ }^{2,4}$ Malformation is mainly sporadic with an unknown etiology, but genetic mutations, teratogenic causes, and some teratogenic agents and drugs, such as theophylline, beclomethasone, and salicylates, are thought to be possible causes. ${ }^{5}$ Recently, it has been established that otocephaly can be caused by new heterozygous or biallelic mutations in the PRRX1 gene in two unrelated infants. ${ }^{6-8}$
From an embryological point of view, it is believed that this lethal malformative complex is the result of a failure of mandibular development as a result of a secondary defect in the migration of neural crest cell. ${ }^{9}$ It is thought that agnathy is major malformation that is associated with ventromedial displacement of the structures of the outer ears (synotia), tongue agenesia (aglossia), small mouth sizes (2-3 mm in diameter) (microstomia), and persistence of the buccopharyngeal membrane. ${ }^{9}$

SAMS can be isolated or associated with other abnormalities, such as holoprosencephaly, neural tube defects, skeletal and skull defects, or internal organs. ${ }^{10}$ The association with holoprosencephaly ranges from 0.8 to $10 \% .{ }^{11}$ This gives rise to Jagtap et al. to accept the presence of four types of otocephaly: (a) Isolated agnathia; (b) Agnathia with holoprosencephaly; (c) Agnathia with situs inversus and internal organ abnormalities; and (d) Agnathia, holoprosencephaly, situs inversus and internal organ abnormalities. ${ }^{12}$ In our case, in addition to holoprosencephaly, there are also defects in the nasal cavity and skull but without defects in the internal organs. Experiments with mice, heterozygous for the Otx2 mutation, provide new insights into the genetic pathogenesis of human otocephaly. ${ }^{13}$ It is discovered that genetic modifications of Otx2, Otmf18, and Otmf2, located on chromosomes 18 and 2, have been found to correlate with the phenotype of otocephaly and are thought to be related to the development of agnathy with holoprosencephaly in humans. ${ }^{1}$ Prenatal diagnosis of otocephaly is extremely difficult and that is why it is rarely reported. ${ }^{1}$

Since its first description by Kerckring in 1717, until this moment, only a little bit more than 100 cases were reported worldwide. ${ }^{9}$ According to Kajiwara et al., in the English-language literature from 1977 to 2016, only 22 cases of pre-diagnosed otocephaly have been reported. ${ }^{14}$ All cases except the reports by Chen et al. were established after the second trimester. ${ }^{15}$ In the last 2 decades, 3D ultrasound devices have provided significant advantages in the prenatal diagnosis of facial abnormalities and have facilitated the assessment of the nature and extent of the anomaly. ${ }^{16}$

Most SAMS cases were identified accidentally after finding other severe anomalies that led to a medical abortion, such as our case. ${ }^{1}$ It is established that the presence of polyhydramnion to be often associated with agnathia. It should be borne in mind that polyhydramnion is rarely observed during the first and early second trimesters of pregnancy, and therefore its absence does not necessarily exclude the presence of agnathy. ${ }^{14}$ 

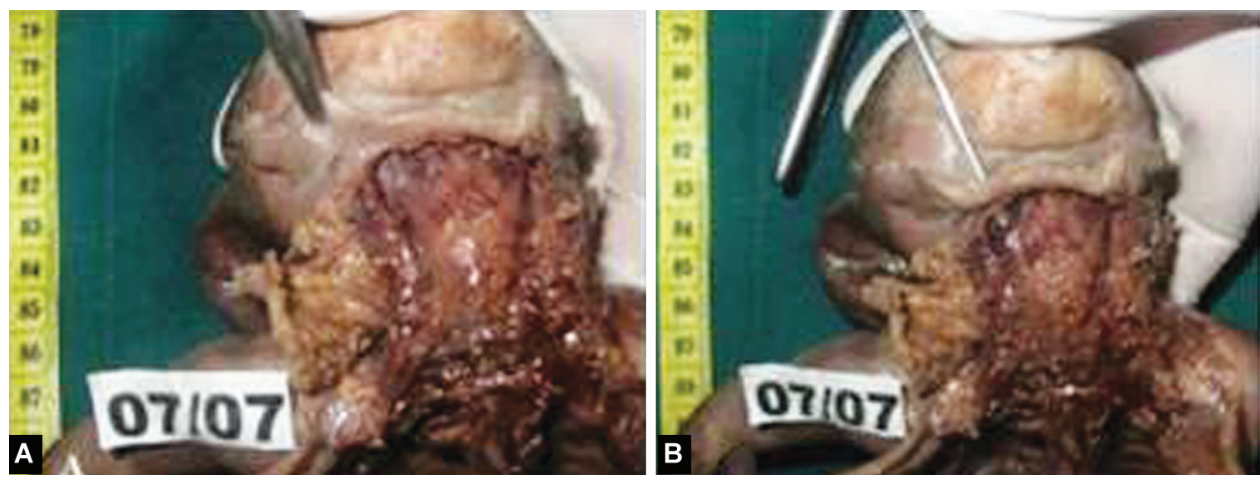

Figs 4A and B: Neck examination—bilateral, auditory cysts of the neck, medially and forward from the ear lobe
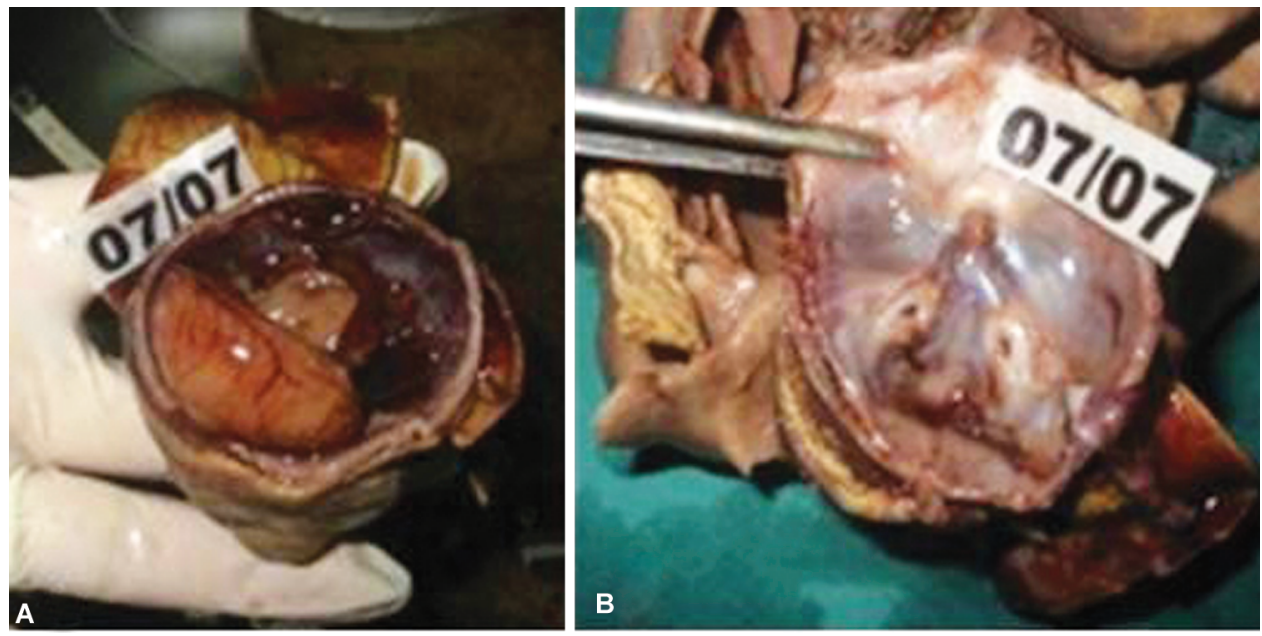

Figs 5A and B: Investigation of intracranial contents: (A) Holoprosencephaly; (B) Sphenoid bone agenesis

\section{Conclusion}

In cases where, at the end of the second trimester of pregnancy, polyhydramnios is detected, inability to visualize the mandible and malposition of ears, otocephaly should be suspected. In these cases, the decision to interrupt pregnancy should be taken by a multidisciplinary team, after an magnetic resonance imaging, which is much better visualizes location of the ears and other facial malformations and the presence of other associated anomalies.

\section{Clinical Significance}

Otocephaly (SAMS) is usually incompatible with life, which is why it is important to perform prenatal diagnosis in order to make prognosis for pregnancy

\section{References}

1. Hwang K-S, Ding D-C, Chang Y-K, et al. Otocephaly. Chin Med Assoc 2007;70(7):298-301. DOI: 10.1016/S1726-4901(07)70009-6.

2. Gekas J, Li B, Kamnasaran D. Current perspectives on the etiology of agnathia-otocephaly. Eur J Med Genet 2010;53(6):358-366. DOI: 10.1016/j.ejmg.2010.09.002.

3. Krassikoff N, Sekhon GS. Familial agnathia-holoprosencephaly caused by an inherited unbalanced translocation and not autosomal recessive inheritance. Am J Med Genet 1989;34(2):255-257. DOI: 10.1002/ajmg.1320340227.
4. Faye-Petersen $\mathrm{O}$, David $\mathrm{E}$, Rangwala N, et al. Otocephaly: report of five new cases and a literature review. Fetal Pediatr Pathol 2006;25(5): 277-296. DOI: 10.1080/15513810601123417.

5. Ibba RM, Zoppi MA, Floris M, et al. Otocephaly: prenatal diagnosis of a new case and etiopathogenetic considerations. Am J Med Genet 2000;90(5):427-429. DOI: 10.1002/(SICI)10968628(20000228)90:5<427::AID-AJMG13>3.0.CO;2-5.

6. Sergi C, Kamnasaran D. PRRX1 is mutated in a fetus with agnathiaotocephaly. Clin Genet 2011;79(3):293-295. DOI: 10.1111/j.13990004.2010.01531.x.

7. Çelik T, Simsek P, Sozen T, et al. PRRX1 is mutated in an otocephalic newborn infant conceived by consanguineous parents. Clin Genet 2012;81(3):294-297. DOI: 10.1111/j.1399-0004.2011.01730.x.

8. Dasouki M, Andrews B, Parimi P, et al. Recurrent agnathia-otocephaly caused by DNA replication slippage in PRRX1. Am J Med Genet A 2013;161A(4):803-808. DOI: 10.1002/ajmg.a.35879.

9. Hisaba WJ, Milani HJF, Júnior EA, et al. Agnathia-otocephaly: Prenatal diagnosis by two- and three-dimensional ultrasound and magnetic resonance imaging. Case report. Med Ultrason 2014;16(4): 377-379.

10. O'Neill BM, Alessi AS, Petti NA. Otocephaly or agnathiasynotiamicrostomia syndrome: report of a case. J Oral Maxillofac Surg 2003;61(7):834-837. DOI: 10.1016/S0278-2391(03) 00160-5.

11. Blaas HGK, Eriksson AG, Salvesen KÅ, et al. Brains and faces in holoprosencephaly: pre and postnatal description of 30 cases. Ultrasound Obstet Gynecol 2002;19(1):24-38. DOI: 10.1046/j.09607692.2001.00154.x. 
12. Jagtap SV, Saini N, Jagtap S, et al. Otocephaly: agnathiamicrostomia-synotia syndrome- a rare congenital anomaly. J Clin Diagnos Res 2015;9(9):ED03-ED04. DOI: 10.7860/JCDR/2015/13636. 6444.

13. Hide T, Hatakeyama J, Kimura-Yoshida C, et al. Genetic modifiers of otocephalic phenotypes in Otx2 heterozygous mutant mice. Development 2002;129:4347-4357.

14. Kajiwara K, Tanemoto T, Nagata $C$, et al. Prenatal diagnosis of isolated agnathia-otocephaly: a case report and review of the literature. Case Rep Obstet Gynecol 2016. 8512351. DOI: http://dx.doi. org/10.1155/2016/8512351.

15. Chen C-P, Chang T-P, Huang J-K, et al. Early second-trimester diagnosis of fetal otocephaly. Ultrasound Obstet Gynecol 2007;29(4):470-471. DOI: 10.1002/uog.3956.

16. Rotten D, Levaillant JM. Two- and three-dimensional sonographic assessment of the fetal face. A systematic analysis of the normal face. Ultrasound Obstet Gynecol 2004;23(3):224-231. DOI: 10.1002/ uog.984. 